\title{
Comarision Of Distributed Power-Flow Controller (DPFC) And Generalized Unified Power Flow Controller (GUPFC) In Power Quality Improvement
}

\author{
D. Raja Reddy ${ }^{1}$, 2Dr. B. Venkata Prasanth ${ }^{2}$ \\ Lecturer, Department of EEE, JNTUACEP Pulivendula, India ${ }^{1}$ \\ Professor \& HOD Department of EEE, QIS College, Ongole, India ${ }^{2}$
}

\begin{abstract}
The present paper describes the steady-state response and control of power in transmission line equipped with FACTS devices. Detailed simulations are carried out on two-machine systems to illustrate the control features of these devices and their influence to increase power transfer capability and improve system reliability. The DPFC is derived from the unified power-flow controller (UPFC) and DPFC and Generalized Unified Power Flow Controller(GUPFC) has the same control capability as the UPFC. The DPFC can be considered as a UPFC with an eliminated common dc link. The active power exchange between the shunt and series converters, which is through the common dc link in the UPFC, is now through the transmission lines at the third-harmonic frequency. In this paper Generalized Unified Power Flow Controller(GUPFC) has been analysed for both open loop and close loop configuration. For this a Single Machine Infinite Bus (SMIB) system is simulated
\end{abstract}

Keywords: FACTS, DPFC, modeling, power transmission, AC-DC power conversion, semiconductor devices, power system control.

\section{INTRODUCTION}

The flexible ac transmission system (FACTS) technology is the application of power electronics in transmission systems [1]. The main purpose of this technology is to control and regulate the electric variables in the power systems. This is achieved by using converters as a controllable interface between two power system terminals. The resulting converter representations can be useful for a variety of configurations. Basically, the family of FACTS devices based on voltage source converters (VSCs) consists of a series compensator, a shunt compensator, and a shunt/series compensator. The static Compensator (STATCOM) [2] is a shunt connected device that is able to provide reactive power support at a network location far away from the generators. Through this reactive power injection, the STATCOM can regulate the voltage at the connection node.

The static synchronous series compensator (SSSC) [2] is a series device which injects a voltage in series with the transmission line. Ideally, this injected voltage is in quadrature with the line current, such that the SSSC behaves like an inductor or a capacitor for the purpose of increasing or decreasing the overall reactive voltage drop across the line, and thereby, controlling the transmitted power. In this operating mode, the SSSC does not interchange any real power with the system in steady-state.

The unified power-flow controller (UPFC) [2] is the most versatile device of the family of FACTS devices, since it is able to control the active and the reactive power, respectively, as well as the voltage at the connection node.
The Unified Power Flow Controller (UPFC) is comprised of a STATCOM and a SSSC [3], coupled via a common DC link to allow bi-directional flow of active power between the series output terminals of the SSSC and the shunt output terminals of the STATCOM [4]. Each converter can independently generate (or) absorb reactive power at its own AC terminal. The two converters are operated from a DC link provided by a DC storage capacitor.

Power Flow Controller (UPFC) which is the novel concept for controlling the bus voltage and power flows of more than one line or even a sub-network. In this paper Generalized Unified Power Flow Controller

(GUPFC) has been analysed for both open loop and close loop configuration. For this a Single Machine Infinite Bus (SMIB) system is simulated. Sine Pulse Width Modulation (SPWM) control strategy has been used for open loop system configuration and PI controller is used for close loop system configuration.

The simulation results have been compared for both uncompensated system and GUPFC in open loop and close loop system configuration which demonstrate the performance after compensating the system. It gives the clear observation of performance improvement in power profile of the power system in given network.

For analysing the THD (Total Harmonic Distortion) level of the system the FFT (Fast Fourier Transform) analysis for GUPFC in open loop and close loop has been done. 
All simulations and analysis has been carried out in MATLAB12a/SIMULINK environment.

\section{DPFC TOPOLOGY}

Similar as the UPFC, the DPFC consists of shunt and series connected converters. The shunt converter is similar as a STATCOM, while the series converter employs the Distributed Static series compensator (DSSC) concept, which is to use multiple single -phase converters instead of one three-phase converter. Each converter within the DPFC is independent and has its own DC capacitor to provide the required DC voltage. The configuration of the DPFC is shown in Figure-1 As shown, besides the key components- shunt and series converters, a DPFC also requires a high pass filter that is shunt connected to the other side of the transmission line and a $\mathrm{Y}-\Delta$ transformer on each side of the line.

The reason for these extra components will be explained later.

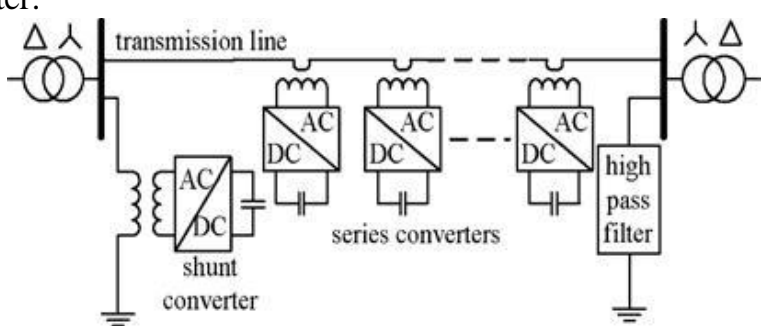

Figure-1. DPFC configuration.

\section{DPFC OPERATING PRINCIPLE AND} CONTROL

A. Active power exchange with eliminated DC link Within the DPFC, the transmission line presents a common connection between the AC ports of the shunt and the series converters. Therefore, it is possible to exchange active power through the AC ports. The method is based on power theory of non-sinusoidal components. According to the Fourier analysis, non-sinusoidal voltage and current can be expressed as the sum of sinusoidal functions in different frequencies with different amplitudes.

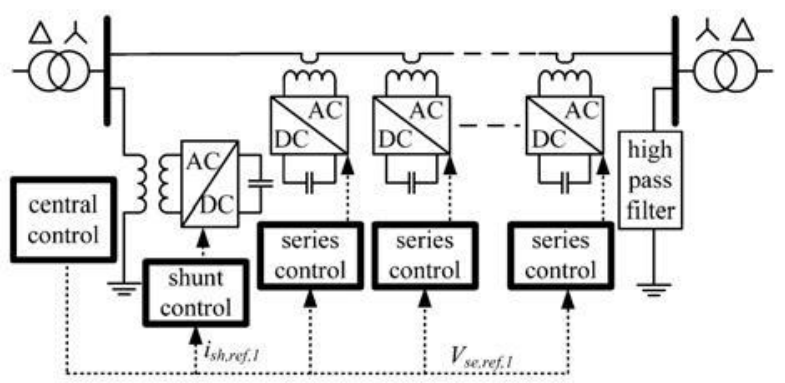

Figure-5. DPFC control block diagram

The harmonic frequency. Figure-2 indicates how the active power is exchanged between the shunt and the series converters in the DPFC system. The high-pass filter within the DPFC blocks the fundamental frequency components and allows the harmonic components to pass, thereby providing a return path for the harmonic components. The shunt and series converters, the high pass filter and the ground form a closed loop for the harmonic current.

\section{B. Central control}

The central control generates the reference signals for both the shunt and series converters of the DPFC. It is focused on the DPFC tasks at the power-system level, such as power-flow control, low-frequency power oscillation damping, and balancing of asymmetrical components. According to the system requirement, the central control gives corresponding voltage reference signals for the series converters and reactive current signal for the shunt converter. All the reference signals generated by the central control are at the fundamental frequency.

\section{Series control}

Each DPFC series converter is locally controlled by its own controller, and the scheme for each series control is identical. To control the series converter, separate control loops are employed for the two frequency components. The $3^{\text {rd }}$ harmonic control loop is used for DC voltage control. The block diagram of the DPFC series converter control is shown in Figure.

\section{Shunt control}

The shunt converter contains two converters. The singlephase converter injects the constant 3rd harmonic current into the grid. The three-phase converter maintains the DC voltage at a constant value and generates reactive power to the grid. The control of each converter is independent. A block diagram of the shunt converter control is shown in Figure.

\section{GUPFC TOPOLOGY}

An innovative approach of utilization of complex FACTS controllers providing a multifunctional power flow management device was proposed in [1] and [2]. There are several possibilities of operating configurations by combing two or more converter blocks with flexibility. Among them, there is a novel operating configuration, namely the Generalized Unified Power Flow Controller (GUPFC) which is significantly extended to control power flows of multi-lines or a sub-network rather than control power flow of single line by a Unified Power Flow Controller (UPFC) or Static Synchronous Series Compensator (SSSC) [4]. The topology shown in the figure consist one shunt connected VSC and two series connected VSC. Here also the shunt converter STATCOM (Static Synchronous Compensator) is used to provide reactive power to the ac system and it will provide the dc supply required for both series connected VSC. The series connected VSCs are SSSC (Series converter or Static Synchronous Series Compensator) which are used to add controlled voltage magnitude magnitude and phase angle in series with the both line. With injection (Series converter or Static Synchronous Series Compensator) which are used to add controlled voltage magnitude and phase angle in series with the both line. With injection of a voltage in series with its host lines the primary function 
Vol. 3, Issue 4, April 2015

The topology shown in the figure consist one shunt connected VSC and two series connected VSC. Here also the shunt converter STATCOM (Static Synchronous Compensator) is used to provide reactive power to the ac system and it will provide the dc supply required for both series connected VSC. The series connected VSCs are SSSC of the GUPFC is shows the signal measurement system which measures source and load voltage \& current, all transformers and capacitor voltage and current. Also the THD (Total Harmonic Distortion) block is used to measure the Each single-phase converter has its own series control through the line.

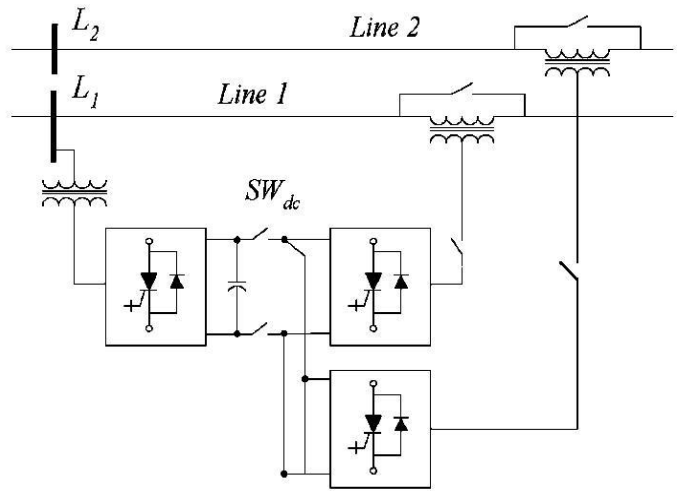

Fig.5.1 Generalized Unified Power Flow Controller (GUPFC)

This controller inputs are series capacitor voltages, line current and series voltage reference in dq-frame. Any series controller fundamental and third harmonic current respectively. Two single-phase phase lock loop (PLL) are used to take frequency and phase information from network [11]. The simulated diagram of series controller is shown in Fig.

THD level of the system. Here the GUPFC compensated system model analysis is done in both open loop and close loop system. Power-flow control in transmission network. The GUPFC controls the magnitude and phase angle of the injected voltages in each line, resulting in four degrees of freedom. Hence, they have the capability to precisely control power flow in two different calculations are done for the common parameters capacitor (C) $2000 \mu \mathrm{F}$, sampling time $25 \mathrm{e}-3 \mathrm{sec}$. and load rating of $(20+\mathrm{j} 6.28) \Omega$ constant for open loop and close loop configuration respectively. Here device is inserted at $0.1 \mathrm{sec}$ in the transmission system model sampling time $25 \mathrm{e}-3 \mathrm{sec}$. and load rating of $(20+j 6.28) \Omega$ constant for open loop and close loop configuration respectively. Here device is inserted at $0.1 \mathrm{sec}$ in the transmission system model for open loop and close loop configuration respectively. Here device is inserted at $0.1 \mathrm{sec}$ in the transmission system model.

Configuration respectively. Here device is inserted at $0.1 \mathrm{sec}$ in the transmission system model sampling time $25 \mathrm{e}-3 \mathrm{sec}$. and load rating of $(20+\mathrm{j} 6.28) \Omega$ constant for open loop and close loop configuration respectively. Here device is inserted at $0.1 \mathrm{sec}$ in the transmission system model. 
INTERNATIONAL JOURNAL OF INNOVATIVE RESEARCH IN ELECTRICAL, ELECTRONICS, INSTRUMENTATION AND CONTROL ENGINEERING

Vol. 3, Issue 4, April 2015

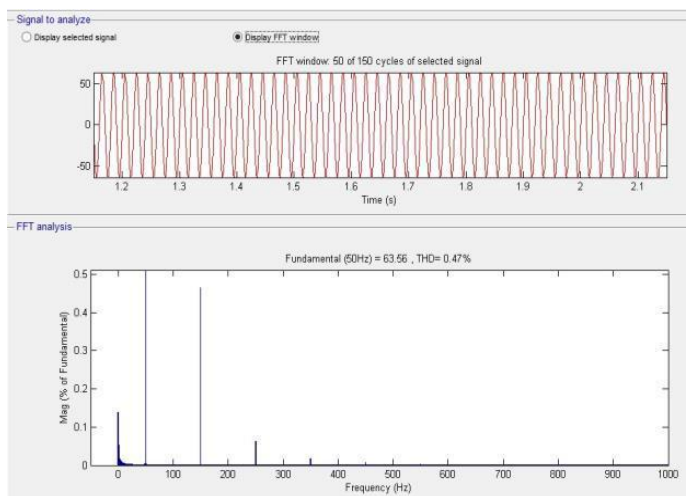

Fig..Current THD (FFT analysis) for O L GUPFC

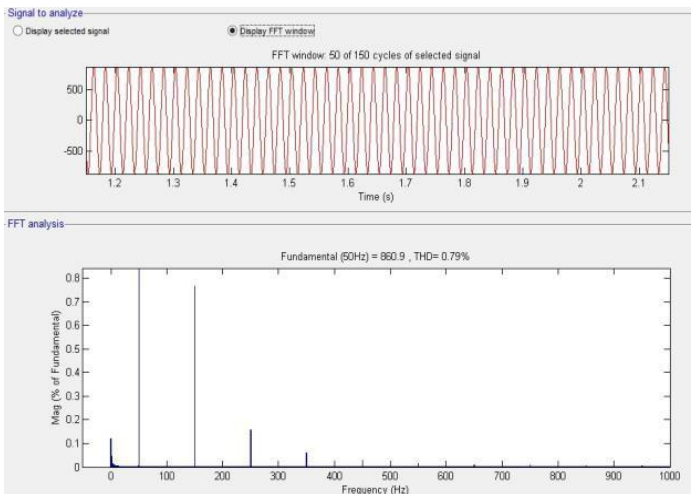

Fig. Voltage THD (FFT analysis) for OL GUPFC

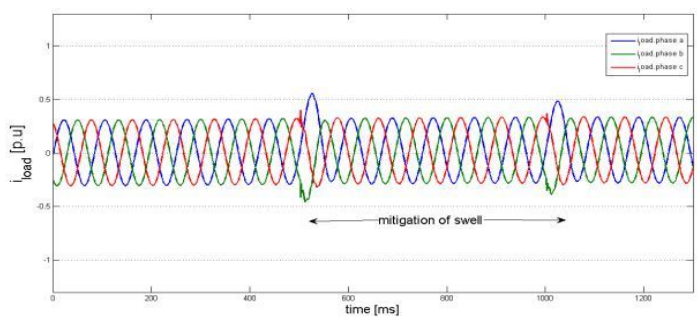

Fig. Mitigation of load current swell with DPFC.

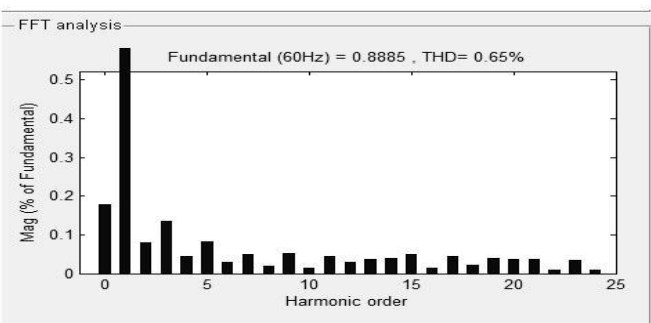

Fig. . The load voltage THD.

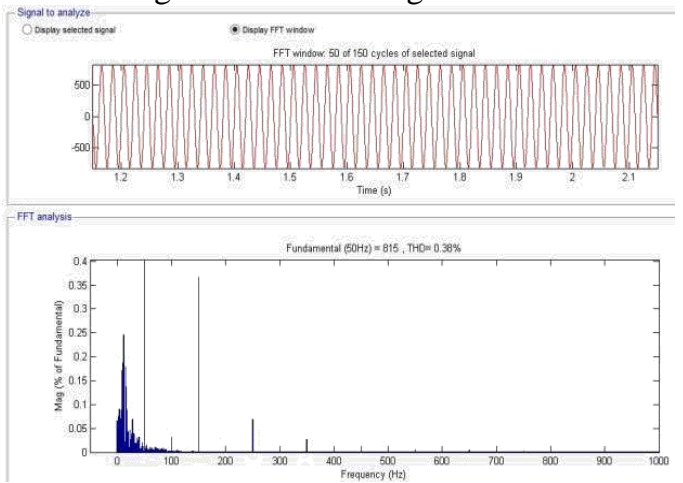

Fig..Voltage THD (FFT analysis) for C L GUPFC

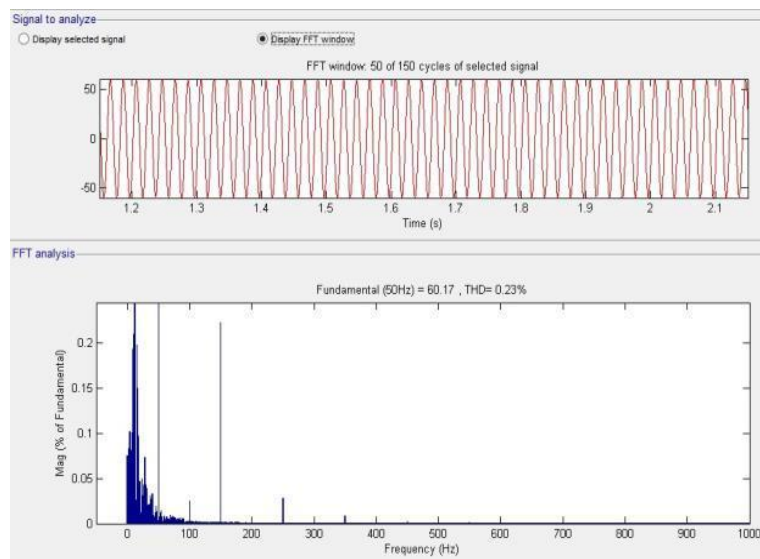

Fig. Current THD (FFT analysis) for GUPFC

\section{CONCLUSION}

The power quality enhancement of the power transmission systems is an vital issue in power industry. In this study, the application of DPFC and GUPFC as a new FACTS device, in the voltage sag and swell mitigation of a system composed of a three-phase source connected to a non-linear load through the parallel transmission lines is simulated in Matlab/Simulink environment. The voltage dip is analyzed by implementing a three-phase fault close to the system load. To detect the voltage sags and determine the three single phase reference voltages of DPFC, the SRF method is used as a detection and determination method. The obtained simulation results show the effectiveness of DPFC in power quality enhancement, especially in sag and swell mitigation.

Introducing GUPFC in the system it is improving the active and reactive power of the network, hence improving the power profile of the system. It is also shown from the results for both open loop and close loop system that the performance of PI control strategy is improved from SPWM control strategy and better performance achieved. The THD (fast Fourier transform) analysis of the load in network for both voltage and current also improved .

\section{REFRENCES}

[1]. J. Faiz, G. H. Shahgholian, and M. Torabian, "Design and simulation of UPFC for enhancement of power quality in transmission lines," IEEE International Conference on Power System Technology, vol. 24, no. 4,2010.

[2]. E. Emanuel and J. A. McNeill, "Electric power quality," Annu. Rev. Energy Environ, 1997.

[3]. N. R. Patne and K. L. Thakre "Factor affecting characteristics of voltage sag due to fault in the power system," Serbian Journal of Electrical engineering. vol. 5, no.1, 2008.

[4]. R. Enslin, "Unified approach to power quality mitigation," in Proc. IEEE Int. Symp. Industrial Electronics (ISIE '98), vol. 1, 1998.

[5]. Singh, K. Al-Haddad, and A. Chandra, "A review of active filters for power quality improvement," IEEE Trans. Ind. Electron. vol. 46, no. 5, pp. 960-971, 1999.

[6]. M. A. Hannan and A. Mohamed, member IEEE, "PSCAD/EMTDC simulation of unified series-shunt compensator for power quality improvement," IEEE Transactions on Power Delivery, vol. 20, no. $2,2005$.

[7]. L. Olimpo and E. Acha, "Modeling and analysis of custom power systems by PSCAD/EMTDC," IEEE Trans. Power Delivery, vol. 17 , no.1, pp. 266-272, 2002. 
Vol. 3, Issue 4, April 2015

[8]. Pohjanheimo and E. Lakervi, "Steady state modeling of custom power components in power $n$ netwoc. IEEE Power Engineering Society Winter Meeting, vol. 4, Jan, pp. 2949-2954,

\section{BIOGRAPHY}

D.RajaReddy received the B,Tech. degree in electrical engineering from the JNTU University, Anantapur, India, in 2009. He received the M.Tech. Degree in Electrical Power engineering from Jawaharlal Nehru Technological University, Ananthapur, India, in 2011. He is Pursuing Ph.D in JNTUA Anantapur.Currently, he is Working as Lecturer in JNTUACEP ,Pulivendula. He is research interests Power Quality and FACTS and Power System Dynamics.

Dr.B. Venkata Prasanth received the B.Tech degree in electrical \& electronics engineering from SK University, Ananthapur, India, in 2000. He received the M.Tech. degree in Electrical Power Systems from Jawaharlal Nehru Technological University, Ananthapur, India, IN 2006.He received Ph.D in 2009 JNTU Hyderabad.Currently, he is working as Professor and HOD in QIS College of Engineering and Technology. He is interests are in power system control design and dynamic load modeling. 